\title{
Ultrafiltration of soybean oil/hexane extract by porous ceramic membranes
}

\author{
Jeffrey Chi-Sheng Wu*, En-Hsien Lee \\ Department of Chemical Engineering, National Taiwan University, Taipei 10617, Taiwan
}

Received 6 November 1997; received in revised form 5 June 1998; accepted 11 September 1998

\begin{abstract}
This study investigated the ultrafiltration of soybean oil/hexane extract (miscella) using porous ceramic membrane. The evaporation energy can be saved in the soybean oil production by pre-separating a portion of hexane through the ceramic membrane. Raw soybean oil/hexane extract with $33 \mathrm{wt} \%$ of oil was used without pretreatment. A cross-flow ultrafiltration was performed using an anodisc membrane with a pore diameter of $0.02 \mu \mathrm{m}$ and thickness of $\sim 1 \mu \mathrm{m}$. The concentrations of oil/ hexane mixture were measured by UV adsorption at a wavelength of $458 \mathrm{~nm}$. The separation mechanism was suggested to be the hindrance diffusion of soybean oil. Agitation in the feed side significantly increased the rejection of soybean oil. A small stage cut could also yield a higher rejection. Above observations were attributed to the reduction of concentration polarization by increasing the shear rate and small permeate flux, respectively. The optimum separation was achieved under the conditions of $4 \mathrm{~kg} / \mathrm{cm}^{2}$ transmembrane pressure, 0.04 stage cut and $120 \mathrm{rpm}$ agitation speed. The concentration of soybean oil decreased from $33 \mathrm{wt} \%$ of feed to $27 \mathrm{wt} \%$ in permeate, that is, near $20 \%$ rejection. A gel-layer polarization model was proposed to estimate the gel concentration and thickness. The gel concentration was found 43-53 wt $\%$. Agitating feed side reduced gel thickness, thus enhanced the rejection and permeate flux. (C) 1999 Elsevier Science B.V. All rights reserved.
\end{abstract}

Keywords: Ceramic membrane; Concentration polarization; Ultrafiltration; Soybean oil; Non-aqueous separations

\section{Introduction}

The capabilities of ceramic membranes include high-temperature durability, sufficient mechanical strength, chemical inertness, organic solvent resistance and unique surface characteristics. Furthermore, these membranes are resistant to biological attack and steam sterilization so that there is less likelihood of bacteria contamination. Such a feature is highly attractive for the food and pharmaceutical industries. Ultra-

*Corresponding author. Tel.: +886-2-23631994; fax: +886-223623040; e-mail: cswu@ccms.ntu.edu.tw filtration or reverse osmosis with membranes can replace conventional food processes, e.g. distillation, thereby minimizing thermal damage and reducing energy consumption [1]. In light of these consideration, this study investigates the macromolecular transport and separation mechanism in porous ceramic membranes. The separation of soybean oil/hexane extract is selected herein because it is a solventextraction process in the food processing industry.

Soybean oil is typically extracted from soybean flakes by hexane in the edible oil process. Raw extract (miscella) normally contains $25-30 \mathrm{wt} \%$ soybean oil. More than $70 \mathrm{wt} \%$ of hexane is removed by distilla- 
tion following steam stripping which consumes most of the energy cost in a typical soybean oil plant [2]. In a related work, Köseoglu et al. [3] examined the feasibility of using the membrane process to remove the solvent from crude vegetable oil. However, the polymeric membranes were damaged by hexane. The ceramic membrane is highly attractive in its resistance to swelling and dissolution in hexane. The steam consumption can be less than the current distillation process if hexane is partially separated by ultrafiltration using ceramic membranes.

Current porous ceramic membranes can only provide partial separation since the pore size is insufficiently small as mentioned later in Section 3. However, to conserve evaporation energy, a pre-separating portion of hexane may still save energy in the process. Soybean oil/hexane system is only one of the typical applications using ceramic membranes. Such membranes can be applied to many liquid-phase systems, including catalyst recovery, wastewater treatment [4], and oil/water emulsion processing [5]. In light of such applications, the transport phenomena must be elucidated.

\section{Experimental}

The soybean oil/hexane extract (miscella) was provided by Jia-Shin Oil and Grease (Taiwan). The extract was directly collected from the solvent extractor without refining. Raw extract typically contained near $33 \mathrm{wt} \%$ of soybean oil, $0.6 \mathrm{wt} \%$ of phospholipids and less than $0.1 \mathrm{wt} \%$ of free fatty acids balanced with hexane. This extract was used herein without any pretreatment. The soybean oil concentrations were measured by UV adsorption (Shimadzu UV-210 A). Raw extract was concentrated to $\sim 90 \mathrm{wt} \%$ by hot water bath to remove hexane at $85^{\circ} \mathrm{C}$. This concentrate was then diluted with various amounts of hexane for the standards of UV calibration. Fig. 1 displays the calibration curve of soybean oil concentration. The UV adsorption of oil/hexane mixtures were measured at a wavelength of $458 \mathrm{~nm}$. The concentrations were subsequently obtained by interpolating calibration curve.

Porous alumina anodisc ( $47 \mathrm{~mm}$ in diameter) were purchased from Whatman (USA). Fig. 2 displays the SEM cross-section of anodisc. The structure of disc

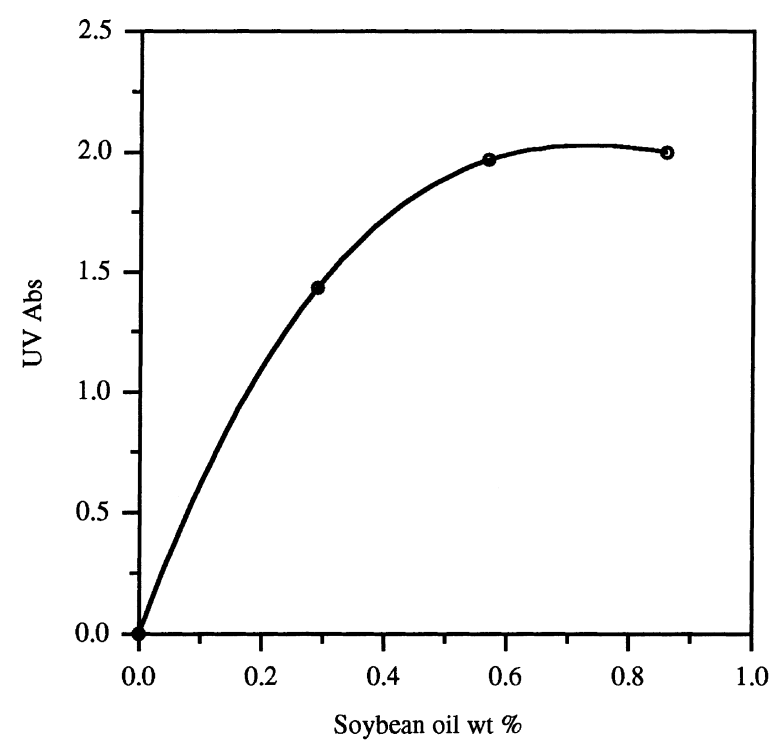

Fig. 1. Calibration curve of soybean oil/hexane mixture by UV absorption.
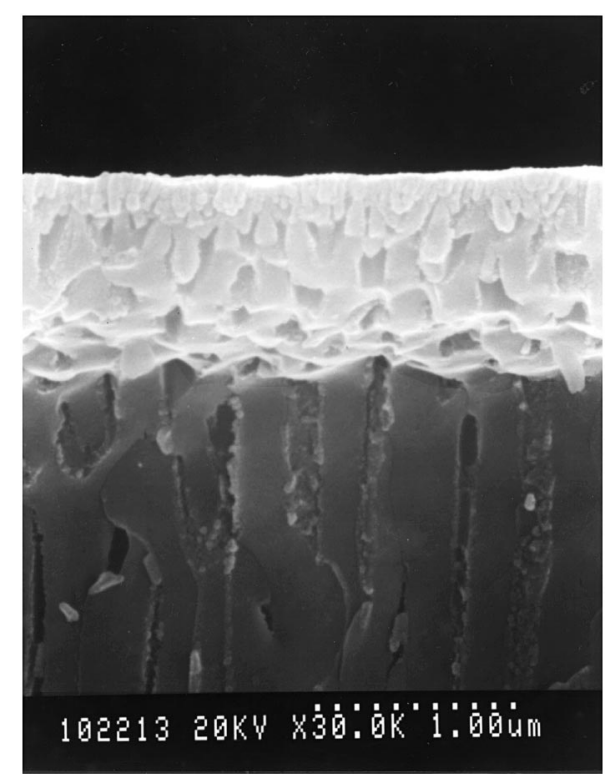

Fig. 2. SEM cross-section of anodisc membrane.

was asymmetric. The pore diameter of top layer was $0.02 \mu \mathrm{m}$ with a thickness of $\sim 1 \mu \mathrm{m}$. Support comprised straight-pore structure and pore diameter was $0.2 \mu \mathrm{m}$ with a thickness of $\sim 60 \mu \mathrm{m}$ [6]. The 


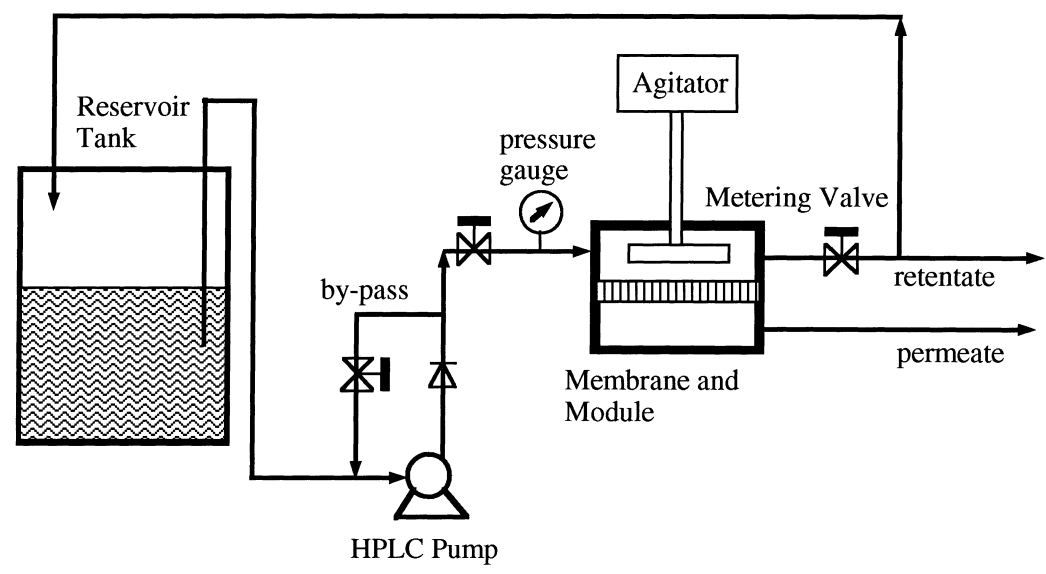

Fig. 3. Schematic diagram of soybean oil extract separation system.

asymmetric structure provided the minimum flow resistance while still retaining excellent mechanical strength. Notably, using such a membrane with a nearly uniform pore size and straight channel would facilitate the analysis of a complex transport phenomena.

The ultrafiltration experiments were performed at room temperature. Fig. 3 schematically depicts the apparatus used herein. Soybean oil/hexane extract was delivered by a HPLC pump (SSI, digital pump series 2 ), under which condition, the flow rate could be adjusted from 0.1 to $40 \mathrm{ml} / \mathrm{min}$. The retentate pressures, which ranged from 101 to $808 \mathrm{kPa}$, were regulated by a metering valve. Transmembrane pressures and flows could be controlled independently by the HPLC pump and the metering valve. Permeate was opened to the atmosphere. The operation of various stage cut at a constant transmembrane pressure was achieved by adjusting the feed flow and metering valve. Fig. 4 illustrates the membrane module which could simulate cross-flow filtration. To increase the shear rate, the space immediately above the membrane surface was agitated by a cross-paddle with an adjustable speed up to $120 \mathrm{rpm}$. The $0.02 \mu \mathrm{m}$ layer was always faced forward the feed side during filtration operation. Permeate flow, depended on transmembrane pressure, ranged from 0.38 to $7 \mathrm{ml} / \mathrm{min}$. Retentate flow, which ranged from 0.7 to $16 \mathrm{ml} / \mathrm{min}$, was recycled back to a reservoir tank. The volume of tank was nearly $5 \mathrm{l}$, which was sufficient to keep constant concentration with recycled retentate in one experi-

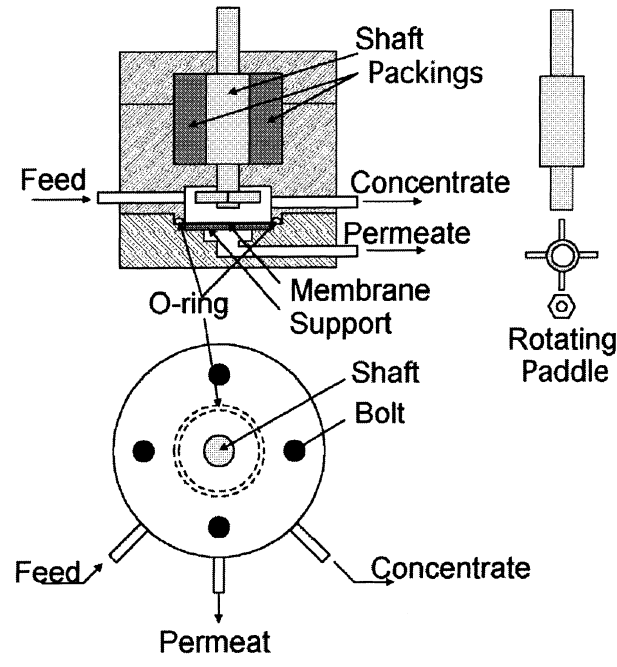

Fig. 4. Membrane module for cross-flow filtration.

ment. The permeate flux changed rapidly during the first $2 \mathrm{~h}$ (see Fig. 7). Therefore, separation data were acquired after $2 \mathrm{~h}$ permeation when a fresh membrane was used in each run. Both retentate and permeate were collected and analyzed their concentrations by UV adsorption simultaneously.

The permeation of pure hexane was intended to measure. However, no transmembrane pressure could be read even at the maximum feed rate $(\sim 40 \mathrm{ml} / \mathrm{min})$. Therefore, the membrane resistance of hexane was considered to be negligible in our experimental conditions. 


\section{Results and discussion}

\subsection{Evaluation of separation performance}

The quality of separation is expressed by rejection, as defined in Eq. (1). Rejection demonstrates how effectively a membrane can separate soybean oil from hexane. The higher the rejection implies a better membrane performance. The quantity of separation can be expressed by stage cut, which calculates the ratio of permeate to feed flow rates. Stage cut can be regarded as the amount of permeate collected with a given feed rate. Operation with a small stage cut requires a longer time or large membrane surface to process a given amount of extract. These two parameters can be used to evaluate the economy of a membrane separation system.

Rejection $=\left(C_{\text {feed }}-C_{\text {permeate }}\right) / C_{\text {feed }}$.

Permeate flux comprises of diffusional and convective flows in the ultrafiltration by a porous membrane (Eq. (2)) [7]. The Peclet numbers were calculated based on the membrane pore $(0.02 \mu \mathrm{m})$, thickness $(\sim 1 \mu \mathrm{m})$, permeate fluxes and estimated diffusivity (Table 2), and found to be much less than 1 . The value of $P e$ implies that diffusional flow would be the dominant factor in permeation [8]. The driving force for diffusion (first term) is the concentration gradient. The separation mechanism of heavy and light molecules is attributed to the diffusivity difference. The second term, convective flow, does not contribute to separation.

$J_{i}=c_{i}\left(v_{i}+u\right)$.

\subsection{Diffusivity and pore size}

Table 1 summarizes the physical parameters of soybean oil and hexane. Soybean oil is a mixture of triglycerides consisting of $\mathrm{C}_{16}-\mathrm{C}_{18}$ fatty acids. Oleic and $\alpha$-linolenic acids are two major components $(>60 \%)$ of unsaturated chains. Soybean oil molecule consists of nearly 60 carbon atoms and molecular weight estimated near $900 \mathrm{~g} / \mathrm{mol}$ with molar volume $\sim 980.39 \mathrm{~cm}^{3} / \mathrm{mol} \mathrm{[2,9]}$. The molecular weight of hexane is $86 \mathrm{~g} / \mathrm{mol}$ with a molar volume of $131.6 \mathrm{~cm}^{3} / \mathrm{mol}$. The molecular diameters of soybean oil and hexane were estimated to be 14.5 and $7.5 \AA$,
Table 1

The physical parameters of soybean oil and hexane

\begin{tabular}{lll}
\hline Properties & Soybean oil & Hexane \\
\hline Density at $25^{\circ} \mathrm{C}$ & $0.918^{\mathrm{a}}$ & 0.659 \\
Viscosity $(\mathrm{cp})$ at $25^{\circ} \mathrm{C}$ & $50.09^{\mathrm{a}}$ & 0.32 \\
Normal boiling point $\left({ }^{\circ} \mathrm{C}\right)$ & $\sim 280^{\mathrm{a}}$ & 68.7 \\
Molecular weight $(\mathrm{g} / \mathrm{mol})$ & $\sim 900^{\mathrm{a}}$ & 86.18 \\
Molar volume $^{\mathrm{b}}\left(\mathrm{cm}^{3} / \mathrm{mol}\right)$ & 980.39 & 131.6 \\
Molecular size $^{\mathrm{c}}(\AA)$ & $\sim 16.1$ & $\sim 7.5$ \\
\hline
\end{tabular}

${ }^{\mathrm{a}}$ Chen et al. [9].

${ }^{\mathrm{b}}$ Molar volume of soybean oil: molecular weight/density.

${ }^{\mathrm{c}}$ Assuming spherical shape, based on molar volume and the correlation of Wong et al. [11].

respectively, from their molar volumes by assuming a spherical shape. The solvent used and its concentration influenced the molecular size of soybean oil [10]. Thus, the molecular size of soybean oil in hexane would differ from that of undiluted form. According to the correlation of Wong et al. [11], the molecular volume of pure component was nearly $75 \%$ of that in the solvent. Thus, the molecular size of soybean oil would be expanded to 16.1 .

The soybean oil/hexane extract could be considered as extremely diluted since the mole fraction of soybean oil was only $\sim 0.045$ (33 wt\% and molecular weight $\sim 900$ ). Therefore, the mutual diffusivity of soybean oil in hexane could be calculated by StokesEinstein equation based on the molecular size and solvent viscosity [12]. The diffusivity of major component (mole fraction $~ 0.955$ ), hexane, would be considered as self-diffusion which could be also estimated according to its molecular size and viscosity by the same method. The diffusion in a narrow pore was slower than that in the bulk solution due to hindrance effect. Davidson and Deen [8] contended that the diffusive hindrance factor was related to the ratio of molecular size to pore diameter. The hindrance of convection was negligible because that factor was found to be near 1. Flow-induced deformation, although another factor influenced the diffusivity, was considered negligible owing to the small permeate fluxes (i.e. small rate of strain) [10]. Table 2 lists the calculated diffusivities of soybean oil and hexane under various pore sizes from the above estimation. The diffusive hindrance effect was substantial for soybean oil, while it was minor for hexane. The diffusivity ratios of soybean oil to hexane were 4.5 
Table 2

The estimated diffusivities of soybean oil and hexane in various pore sizes at $298 \mathrm{~K}$

\begin{tabular}{llll}
\hline Pore size & $\begin{array}{l}\text { Diffusivity } \\
\left(\mathrm{cm}^{2} / \mathrm{s}\right) \times 10^{6}\end{array}$ & $\begin{array}{l}\text { Diffusivity ratio of hexane } \\
\text { to soybean oil }\end{array}$ \\
\cline { 2 - 3 } & Soybean oil & Hexane & \\
\hline$\infty$ & $9.08^{\mathrm{a}}$ & $40.8^{\mathrm{b}}$ & 4.5 \\
$0.02 \mu \mathrm{m}^{\mathrm{c}}$ & 6.82 & 36.7 & 5.4 \\
$0.01 \mu \mathrm{m}^{\mathrm{c}}$ & 3.18 & 32.6 & 10.3 \\
$5 \mathrm{~nm}^{\mathrm{c}}$ & 0.73 & 19.6 & 26.8 \\
\hline
\end{tabular}

${ }^{\mathrm{a}}$ Mutual diffusivity by Stokes-Einstein equation [12].

${ }^{\mathrm{b}}$ Self-diffusivity by Stokes-Einstein equation [12].

${ }^{c}$ Diffusivities in pores based on Davidson and Deen correlation models [8].

and 5.4 in the bulk and the $0.02 \mu \mathrm{m}$ pore, respectively. The ratios became larger as the pore size reduced. The separation mechanism of soybean oil/hexane, thus, suggested the diffusivity difference. Molecular sieving could not be achieved for the current membranes (i.e. $0.02 \mu \mathrm{m}$ pore). Such a membrane was expected to give only marginal separation. However, the diffusion difference could be significantly increased if the pore size reduced to less than $5 \mathrm{~nm}$. Consequently, rejection should expect to increase.

\subsection{Concentration polarization}

Concentration polarization profoundly influences ultrafiltration. Soybean oil accumulated on the surface of membrane during filtration. Thus, the separation efficiency declined owing to the rising concentration gradient of soybean oil across membrane. Concentration polarization can be mitigated by increasing the turbulence of cross-flow or the shearing stress near the membrane surface. Agitation in the retentate side is an effective means of lessening concentration polarization. Consequently, the separation performance can be greatly enhanced.

Fig. 5 presents the effects of transmembrane pressure and agitation speed on the rejection. According to this figure, the rejection decreased with an increase of the transmembrane pressure without agitation. However, the influence of transmembrane pressure diminished with agitation, particularly at a higher speed. As expected, the rejection was significantly enhanced with agitation. In addition, permeate fluxes increased with agitation speed. Zeman and Wales reported that the decrease of rejection with an increase $\Delta p$ reflected both concentration polarization and/or the shearinduced solute distortion at a higher transmembrane pressure [13]. Obviously, agitation facilitated the minimization of the concentration polarization, thereby increasing the rejection as well as permeation. The influence of solute distortion might be obscured by agitation or became negligible at such transmembrane pressures.

Fig. 6 illustrates how stage cut influences the rejection under the condition of agitation speed $120 \mathrm{rpm}$ and transmembrane pressure $404 \mathrm{kPa}$. The smaller the stage cut implies a higher rejection. A small stage cut was comparable to small permeate flux. Concentration polarization could be minimized with small permeate flux. Furthermore, small permeate flux reduced the convective flow. Permeation was majorly attributed to diffusional flow (Eq. (2)), thereby enhancing the separation of soybean oil. The optimum separation occurred at a small stage cut near 0.04 under our experimental conditions. The rejection was $\sim 20 \%$, i.e. the soybean concentration decreased from $35 \mathrm{wt} \%$ of feed to $27 \mathrm{wt} \%$ of permeate.

\subsection{Gel-layer polarization model}

Fig. 7 presents the permeance versus filtration time with various transmembrane pressures. The permeance decreased from 10 to $\sim 2 \times 10^{-8} \mathrm{~g} /(\mathrm{min}$ $\mathrm{cm}^{2} \mathrm{~Pa}$ ) rapidly even with an increasing transmembrane pressures for the first $2 \mathrm{~h}$. Then the permeance decreased to near $1 \times 10^{-8} \mathrm{~g} /\left(\min \mathrm{cm}^{2} \mathrm{~Pa}\right)$ under a constant transmembrane pressure $(707 \mathrm{kPa})$, and it remained there after decreasing pressures. In addition to soybean oil, raw extract contained a small amount of phospholipids which could form reverse micelles and accumulate on the membrane surface, thus increase the flow resistance [14]. Further increasing the transmembrane pressure appeared to negligibly influence the flux. This observation suggests that the accumulation of solute (i.e. soybean oil and phospholipids) formed a gel layer on the surface of membrane. The formation of gel depends on the size, shape, chemical structure of solute and degree of solvation, but is not influenced by filtration operation. The permeate flux could be expressed by the following equation based on the gel-layer polarization 


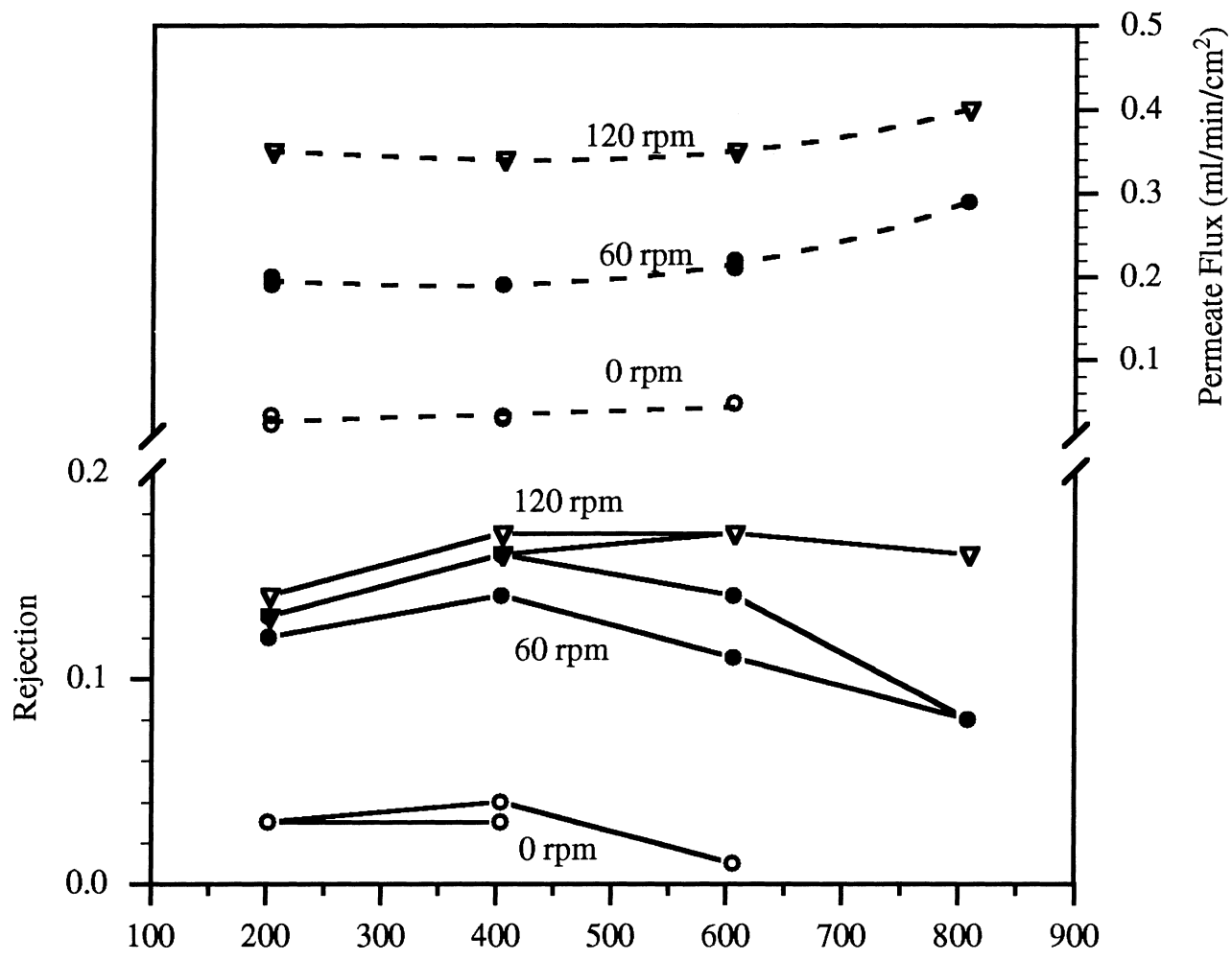

Transmembrane Pressure $(\mathrm{kPa})$

Fig. 5. Effect of agitation speed on separation performance.

model [15]:

$J=k \ln \frac{\left(C_{\mathrm{g}}-C_{\mathrm{p}}\right)}{\left(C_{\mathrm{b}}-C_{\mathrm{p}}\right)}$,

where $k$ denotes the mass transfer coefficient, equal to the ratio of diffusivity and gel thickness, $D / \delta$. The gel concentration became a constant once the gel formed. It was not affected by transmembrane pressure and permeation. The mass transfer coefficient $(k)$ could be omitted in Eq. (4) by properly arranging Eq. (3). Therefore, the gel concentration $\left(C_{\mathrm{g}}\right)$ could be estimated from the experimental data of $J$ 's and $C_{\mathrm{p}}$ 's. The mass transfer coefficient could be calculated by Eq. (3) once $C_{\mathrm{g}}$ was obtained:

$$
\left[\frac{\left(C_{\mathrm{g}}-C_{\mathrm{p}_{1}}\right)}{\left(C_{\mathrm{b}}-C_{\mathrm{p}_{1}}\right)}\right] \frac{J_{2}}{J_{1}}=\frac{\left(C_{\mathrm{g}}-C_{\mathrm{p}_{2}}\right)}{\left(C_{\mathrm{b}}-C_{\mathrm{p}_{2}}\right)} .
$$

The average values of $C_{\mathrm{g}}, k$ and $\delta$ were calculated from 3 to 5 different fluxes at each agitation speed. Table 3 summarizes those values of three agitation speeds. The concentration of gel layer $\left(C_{\mathrm{g}}\right)$ was nearly at a constant level, which was consistent with this model. Notably, the mass transfer coefficients (k) significantly increased with agitation speed. The

Table 3

The average values of mass transfer coefficient, gel concentration and thickness under different agitation speeds

\begin{tabular}{llll}
\hline Agitation speed (rpm) & $C_{\mathrm{g}}(\mathrm{wt} \%)$ & $k\left(\mathrm{~cm}^{3} / \mathrm{s} \mathrm{cm}^{2}\right)$ & $\delta(\mathrm{cm})$ \\
\hline 0 & 52.6 & 0.013 & $5.2 \times 10^{-4}$ \\
60 & 44.2 & 0.18 & $3.8 \times 10^{-5}$ \\
120 & 42.7 & 0.37 & $1.8 \times 10^{-5}$ \\
\hline Transmembrane pressures $202-808 \mathrm{kPa}$, diffusivity & $D=6.82 \times$ \\
$10^{-6} \mathrm{~cm}^{2} / \mathrm{s}$ (Table 2).
\end{tabular}




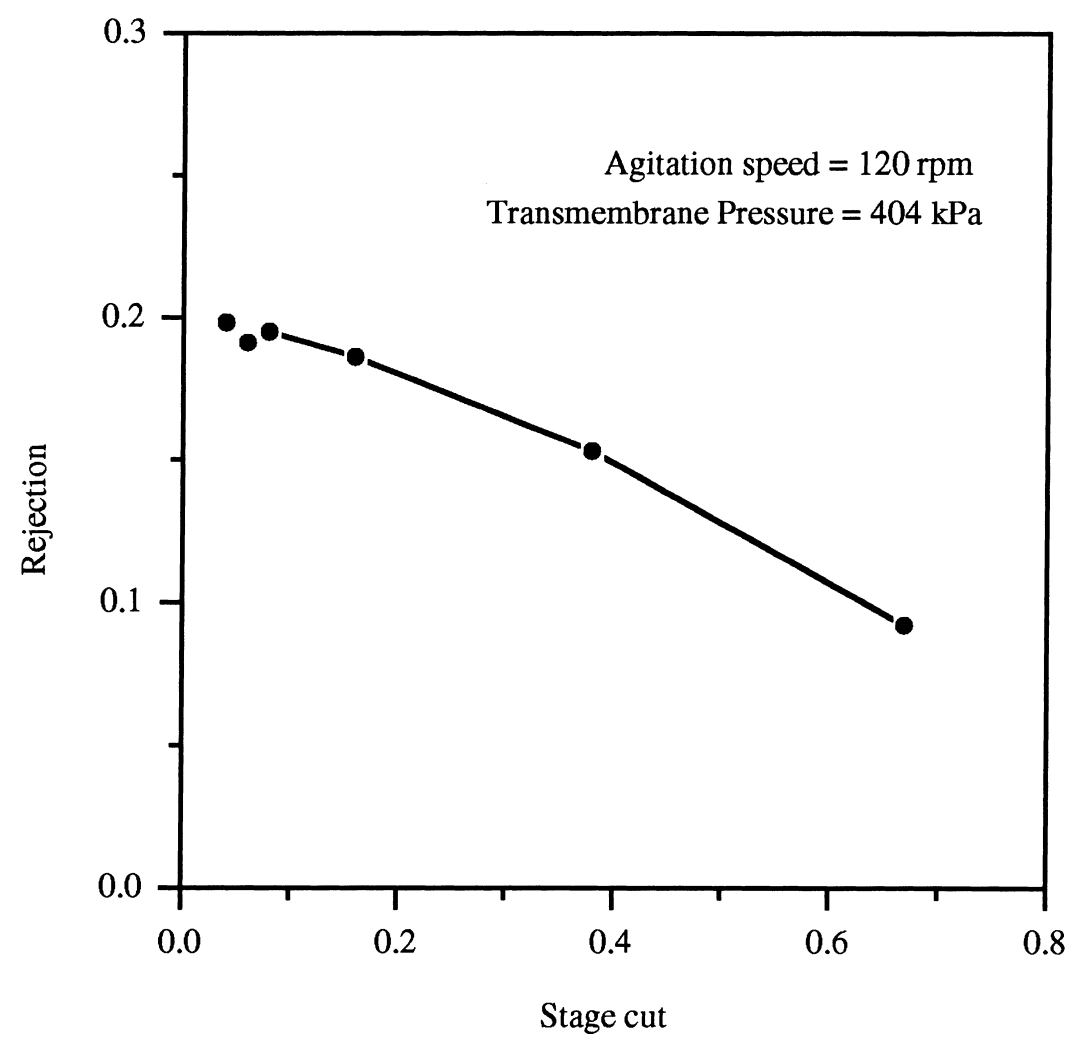

Fig. 6. Effect of stage cut on separation performance.

thinner gel layers indicated that gel-layer polarization was lessened by increasing the shear rate, i.e. agitation.

\section{Conclusion}

This study demonstrates the feasibility of separating soybean oil/hexane extract by using anodisc membrane. Ceramic membrane is promising for solventextraction processes in the food industry. Concentration polarization is an important phenomenon and can be reduced by the feed-side agitation. Therefore, agitation increases rejection. Although a higher rejection can be obtained at small stage cut, sufficient membrane area is necessary to process large quantity of extract. The diffusivity difference of soybean oil and hexane was proposed by the separation mechanism in this system. Until now, the membrane with a pore size of $0.02 \mu \mathrm{m}$ still insufficiently separate the soybean oil/hexane extract. The rejection is too low for economic purposes. Results presented herein suggest that a small pore size is essential for efficient separation. However, the permeate flux usually becomes low when the pore size is reduced. This finding implies that a large membrane surface area is necessary. From an industrial perspective, current rejection would be too low to be practical. Multiple stages with recycles can be applied to increase the overall rejection.

\section{Nomenclature}

$c, C \quad$ concentration $\left(\mathrm{g} / \mathrm{cm}^{3}\right)$

$C_{\mathrm{b}} \quad$ solute concentration of bulk solution $\left(\mathrm{g} / \mathrm{cm}^{3}\right)$

$C_{\mathrm{g}} \quad$ solute concentration of gel $\left(\mathrm{g} / \mathrm{cm}^{3}\right)$

$C_{\mathrm{p}} \quad$ solute concentration of permeate $\left(\mathrm{g} / \mathrm{cm}^{3}\right)$ 


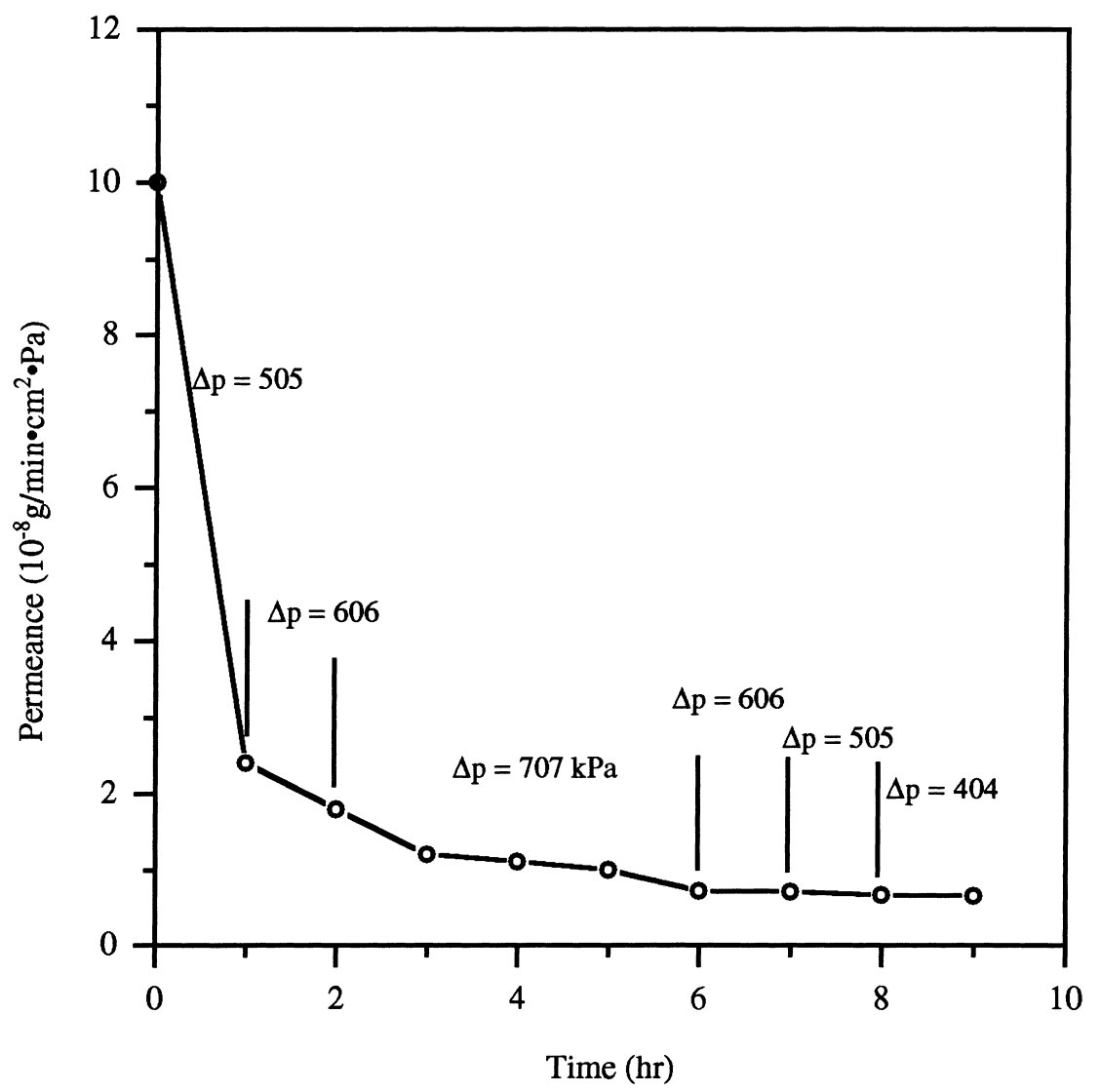

Fig. 7. Permeation with various transmembrane pressures.

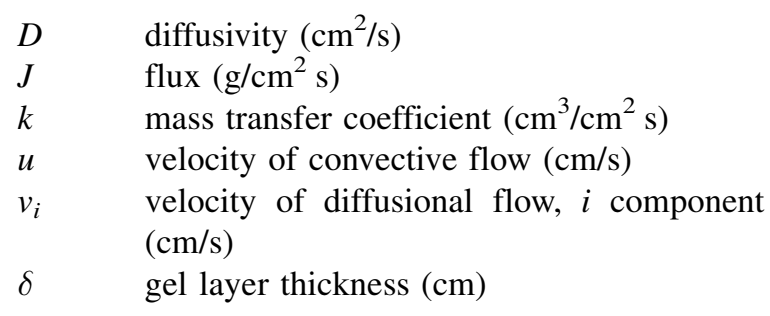

\section{Acknowledgements}

The authors would like to thank the National Science Council, Republic of China on Taiwan, for financially supporting this research under Contract no. NSC 85-2214-E-002-010. Mr. T.S. Kuo of CTCI and the Jia-Shin Oil and Grease company are also appreciated for providing information regarding soybean oil production.

\section{References}

[1] F.P. Cuperus, H.H. Nijhuis, Applications of membrane technology to food processing, Trends Food Sci. Technol. 4 (1993) 277.

[2] Kirk-Othmer, Encyclopedia of Chemical Technology, vol. 9, pp. 795-813 and vol. 21, pp. 417-428, Wiley, New York, 1980.

[3] S.S. Köseoglu, J.T. Lawhon, E.W. Lusas, Membrane processing of crude vegetable oils: pilot plant scale removal of solvent from oil miscellas, J. Am. Oil Chemist's Soc. 67(5) (1990) 315.

[4] F. Gadelle, W.J. Koros, R.S. Schechter, Ultrafiltration of surfactant and aromatic/surfactant solutions using ceramic membranes, Ind. Eng. Chem. Res. 35 (1996) 3687.

[5] R.J. Lahiere, K.P. Goodboy, Ceramic membrane treatment of petrochemical wastewater, Environ. Progr. 12(2) (1993) 86.

[6] C.C. Huang, C.S. Wu, Porous Zirconia membrane by sol-gel method using homogeneous hydrolysis technique, J. Chin. I. Ch. E 28(1) (1997) 61.

[7] M. Mulder, Basic Principles of Membrane Technology, Kluwer Academic Publishers, Dordrecht, Netherlands, 1991, pp. 186-188. 
[8] M.G. Davidson, W.M. Deen, Hydrodynamic theory for the hindered transport of flexible macromolecules in porous membranes, J. Membr. Sci. 35 (1988) 167.

[9] S. Chen, E. Wang, P. Yang, P, Source Book of Soybean and Products, American Soybean Institute, 1986, pp. 88-91.

[10] W.M. Deen, Hindered transport of large molecules in liquidfilled pores, AIChE J. 33(9) (1987) 1409.

[11] M.W. Wong, K.B. Wiberg, M.J. Frisch, Ab initio calculation of molar volumes: comparison with experiment and use in solvation models, J. Comput. Chem. 16(3) (1995) 385 .
[12] R.B. Bird, W.E. Steward, E.N. Lightfoot, Transport Phenomena, Wiley, New York, 1960, pp. 514-515.

[13] L. Zeman, M. Wales, Steric rejection of polymeric solutes by membranes with uniform pore size distribution, Sep. Sci. Technol. 16(3) (1981) 275.

[14] L. Lin, K.C. Rhee, S.S. Köseoglu, Bench-scale membrane degumming of crude vegetable oil: process optimization, J. Membr. Sci. 134 (1997) 101.

[15] H. Niemi, S. Palosaari, Calculation of permeate flux and rejection in simulation of ultrafiltration and reverse osmosis processes, J. Membr. Sci. 84 (1993) 123. 